\title{
Instilling Joy in a Digital Age
}

\author{
Dean Shareski
}

\begin{abstract}
In this interview, digital consultant and author Dean Shareski talks about the fundamental aspects of authentic learning: joy, wonder, play, and community. He believes that technology can bring a sense of fun and curiosity to the classroom by allowing students to do things they couldn't do before, like editing photographs or meeting a scientist from another part of the world. School communities can now share their innovations with the community at large and also with schools in different countries. Teachers, he says, should see themselves as artists and not be afraid to play and explore new opportunities. As final advice to teachers and parents, he suggests that we let kids be kids and experience the joy of childhood.
\end{abstract}

Can you tell us about how you became a digital learning consultant?

Probably about the mid-90s, technology started becoming more and more prevalent in schools and as a classroom teacher I was certainly really curious and interested in that. Our school had a professional development day and they were asking people to share about new things. It was the first time I had a digital camera and I thought this was really interesting and thought about the possibilities. I remember doing one of the very first adult workshops that I'd ever done and it really pushed me down a path. I got some good feedback around that, but also my own curiosity around what can digital do for teaching and learning. From there I was given some opportunities which were really critical for me to work not only with my classroom, but I also was given a quarter time to work with other teachers supporting technology. There was a lot more incentives from within the district, but also provincially around moving forward with technology. I took advantage of all those opportunities and when a position opened up in our school division, I jumped at it and was fortunate enough to be given that position. That's where I really took on that role of digital consultant in the school division and then from there it continued. That's been obviously a theme in my career moving forward. I was a classroom teacher for 14 years and taught everything in elementary. Just like so many of us, that was sort of my grounding ... very much just tied to a classroom and doing the regular things that all teachers do.

In your book, "Embracing a Culture of Joy," you talk about fundamental aspects of all authentic learning comprising joy, wonder, play, and community. Can you tell us about these important dimensions of learning?

I've always felt in some respects as if we've over-complicated learning and education. For me it was an issue of let's get down to what really matters and strip away a lot of ... not to say that they weren't important conversations in all kinds of areas. But for me, what is at the core of what it means to be a learner, and in particular, not in and around schools, just learning in general. Those fundamental things, 
joy, play, wonder, and community, those aren't specific to school. I think those are generic to a life of learning. I wanted to think about learning beyond just the classroom, but also in the classroom. Those are the elements that resonated with me, and as I've been able to share that idea with others, has been resonating with other people. I'm always very careful to say: "Just because you write a book doesn't make you an expert." I'm not a researcher so I can't produce a load of data for people to examine: are these actually the things? I don't proclaim these are the only principles of great learning, but for me they are fundamental and I'm trying to push conversations around those ideas of what that means and how it means to be intentional with those ideas.

How do you define "joy"?

That's a question that, although I wrote about it and speak about it on a regular basis, I'm continually looking for, "What does that mean?" I start with a definition and if you take it right from Webster's it talks about this emotion, "an expression of well-being." And there is an outward expression around that. I refer to moments that in a classroom everybody has experienced: everybody has experienced that moment when the bell rings and nobody moves because you're in the middle of a story-and for that moment there is this joy of, "I'm in the moment. I'm in the right place. This is where I want to be. This is the thing I want to work at." Those are certainly the moments of "eureka" when students are working on a project. The word that is probably most commonly used today is "engagement." That's really what I'm talking about: "I'm doing this for no other reason than I love this and I want to pursue this idea or whatever I'm working on." That's kind of how I define joy and I think it looks like a lot of different things: it might look different in a kindergarten class as it would in other places. It's this intuitive sense of well-being, but also in an outward expressive way.

How important are the aspects of play and wonder?

Play is a really important one. As somebody who taught early elementary, of course it's very easy to see that. Seymour Papert talks about the fact that playfulness is an intellectual pursuit. And that's not something that we typically as older adults have taken, because play has been something that I feel like we do early in life, and then when we figure things out we say, "Okay, enough with the play time, let's get serious about this thing." There are a number of writings ... I know Douglas Thomas and John Seely Brown talk about the fact that the world is in such constant change and flux now, that if you aren't someone who is willing to play and explore new opportunities, you're really missing out on a new culture of learning.

When I think about play, it's this willingness to say, "Let's try something new," and not be so tied to the outcome. I think it is paired with reflection, so it's not, "Let's just do something for the sake of it." I think it is tied to, "Let's pull back; let's try this" and say, "How did that work? Did that seem to make a difference? Is there something we can continue to look at?" I think that "wonder" is maybe backing up a step to a sense of noticing things. Ellen Langer, she's written a lot of books on mindfulness, when she talks about mindfulness she's not talking about meditation or any of those other things which are certainly part of that conversation. She's just talking about noticing, and I think that's such an important disposition 
to what wonder is ... seeing simple things that you hadn't noticed before ... everyday kinds of experiences. Wonder isn't necessarily these "wonders of the world" or "huge phenomena" that we typically think of as "wondrous." I think it's in noticing the everyday things. I love the book by Robert Fulghum, "All I Really Need to Know I Learned in Kindergarten" where he talks about the plant and the seed, and you put that little seed in the cup and somehow that thing grows! Every time we see that it should blow us away. Every time we see a sunset or see something happen in nature ... that should provoke us to wonder. Again, I think that's where that starts and the playfulness is almost like the acting upon that wonder: "What can we do with that? How can we pursue these wonders that we have?"

You give examples in your book about how digital technologies can engage students in joyful learning and can also be used to showcase joyful learning. Can you describe a few examples?

There is a new app that certainly comes out every day, and not to see that as an exclusive path, but it is one example of, "We can try this new technology that allows us to ... even just around photography that allows you to clone something or put yourself in the background and position you in a new light." Those are really playful things, but also, "Wow! We can do something that we couldn't do before!" When I think about technology in particular, that's always a fundamental question for me: "What can we do now that we couldn't do before?" This conversation that we're having right now: that's not something that was really possible 20 or 30 years ago, that you could have a visual connection with another human being.

When I think of technologies that bring joy: bringing a scientist into your classroom to talk about polar bears (we just did that a few weeks ago). You're broadcasting to schools all over the world, talking about the problem we have in Churchill, Manitoba and the impact that that has around the world. Those global kinds of connections, the ways in which we can communicate and share that joy. Because, again, that ties back to the idea of community, we're sharing back to our local community, our parents, but also the world that says, "Hey, we're doing something interesting and maybe somebody else from some other part of the world might find this interesting too and would love to work with us or have us teach you." Those are really opportunities that technology provides us that we didn't have to before to really enhance and amplify those joyful learning experiences.

You make the case that teachers should be artists first. Can you tell us why?

When I first began teaching in 1989, there seemed to be a real push toward a standardization-and I don't mean that even in a negative way. But how do we ensure, first of all, that all students are given the same opportunities, which is an important conversation. But along the way, I felt like the message became, "How do we be all the same"? People would say, "A kid in grade four in one part of the province should have the same experience as a kid in another part of the province." While I understood that and what the goal was, part of it sort of reduced teaching and learning to a real science. When people asked the question, "Is teaching a science or an art?", everybody will say, "Both." However, I want to lean more toward: "What if we thought of ourselves as artists first"? If you ask a musician, "Are you a technician or an artist?", most musicians will say, "I'm an artist." There are high degrees of technical aspects and science involved in becoming a musician, but that's not how they see themselves. They see themselves as an artist. So, I begged the question: "What if as teachers we saw ourselves as artists?" 
What I mean by that: the idea that each of us brings something individual and unique to the experience, and if teaching and learning is indeed a human experience first and foremost, beyond that content and the pedagogy, it's a human experience, then that human experience needs to be spoken about, thought about, and leveraged in whatever way that is. It starts by teachers seeing themselves as an artist: "What do I bring to this that's unique, special, and comes from the heart?"

You indicate that it is important for teachers to identify their unfair advantage. Can you talk about this?

That particular phrase came to me when I was listening to a podcast a few years ago called "Start-up." The podcast was about a guy trying to actually build a new company, which was ironically enough a podcasting company. He was meeting with a venture capitalist ... he was trying to obviously get this person to invest in his business ... he was giving all his business plans and how he was going to make money ... and the guy finally said, "Not interested in that. I want to know what your unfair advantage is? I want to know what it is that you do that nobody else does?" Again, that really ties with that notion of being an artist, that I think teachers need to be intentionally thinking about, "What do I bring to the table that nobody else can bring?" And it can be the simplest thing. I remember teachers who once a month would bring cupcakes to school or something like that. People often look at those things as being just secondary or inconsequential, but they aren't. Those little things that people do and the stories that they tell make such a big difference. I really encourage teachers to think about how to be an interesting person, talk about the books that you've read, the movies you've went to, the hobbies that you have. If you think about some of the messages that teachers have been given over the years around, "They don't need to know who you are as a human being. You're there to teach content!" No, you're not there to teach content, you're there to teach children! And that requires a connection, so why not take advantage of you as an individual? That unfair advantage is a way I hope teachers see themselves as offering something unique and special that maybe nobody else can do just the way they do it.

You have argued that gratitude is an important form of validation for teachers and how infrequently this occurs in educational settings. Can you elaborate?

When I moved from working in a school district to my current job with "Discovery Education," which is a for-profit company, I was struck by how much gratitude is part of that culture. I've never worked for another company before so I don't want to make that a blanket statement. It was just my experience working with this group of people: how intentional they were about thanking you-thanking me for doing my job, not even doing anything extra or out of the ordinary. I would do my job and I'd have somebody from some department say, "Boy, I really just want to thank you for this ..." And it wasn't just a thank you and that was it. It was explicit: "You did this really well and you really made this impact here." They would really speak into my life around the impact I made. It struck me and I thought: "When you work in a school you see adults doing amazing things all day long for children, and I don't know why, but for some reason we just don't do a very good job of pointing that out." Maybe part of it is just sort of the busyness of the day-it's frantic and people are moving and sometimes there's little time to pause and stop-but I know what a difference it makes. 
It was just yesterday on Facebook I saw a post from a parent thanking a principal that I know from Texas and wrote this very long thing saying: "You must get this all the time, but I just want to say how it important was ..." The principal had written a note to this little guy in her school who had been away sick for a couple of days - it wasn't anything serious_and had sent him a little handwritten postcard. And what an impact that made on the parent and the child ... this amazing impact that gratitude has. It's one of the things and I've said it to leaders: "You've got all these initiatives that you're trying to do and that's great. But if you just decided to somehow double whatever gratitude you give out, that would have far more impact than any strategy or plan that you have right now." For some reason, education is just not very good at extolling gratitude.

Lastly, do you have any advice for educators and parents on the importance of joy in childhood?

The reason I talk about joy ... it's a little bit of a pushback to some of the ideas—I don't say that they're bad-but they have taken us down not a great road. Things like standardized testing, the accountability movement- $I^{\prime} m$ not saying those are bad - I'm just saying that joy often got lost in those conservations. A more recent one that I'm quite concerned about is what I've called "the war on childhood." What I mean by that is a continual pressure for kids to succeed and take away their childhoodeverything from this whole "helicopter approach" to parenting where we just don't let kids be kids. There is a school in North Bay, Ontario that decided it didn't want kids to do cartwheels any morenot because anybody got hurt-but because they could get hurt. Have we gone too far in that direction that we're robbing children of this really special time in their lives? You only get to be a kid for a very short period of time and could we maybe help slow it down. Not that schools are the defining answer to that. Obviously, parents are much important in that conversation than schools are. But could schools and educators think about: "How do we allow kids to be kids?" And even as they move through high school, with all the mental health issues, adults play a really important role in helping kids see what a healthy adult life looks like. One of the quotes that I share all the time is from Erica Bauermeister: "Adults need to have fun so children will want to grow up." That statement continues to resonate: What kind of a model can we be for kids?

The part that I'm concerned about now is that we're really not letting our children be children ... it's such a wonderful time in life. I think back to my own childhood that was amazing and again, it was a different time and things aren't the same, but I do want all children to have that childhood experience that involves really intense moments of play, wonder, and belonging, and not be worried about what life is going to be like in 10 or 20 years or being future ready. Instead, childhood should be protected.

\section{References}

Fulghum, R. (1988). All I really need to know I learned in kindergarten: Uncommon thoughts on common things. Villard Books, United States.

Shareski, D. (2016). Embracing a culture of joy. Solution Tree Press: Bloomington, IN. 
Dean Shareski is the Community Manager for Discovery Education Canada. He taught grades one through eight for 14 years and spent nine years as a digital learning consultant for Prairie South School Division in Moose Jaw, Saskatchewan. In addition, he is an Adjunct Professor at Wilkes University. His blog consistently ranks among the top educational blogs. In 2010, he won the ISTE Award for Outstanding Leader of the Year. Dean has had the opportunity to speak to a variety of education audiences both nationally and internationally. He has recently authored "Embracing a Culture of Joy" and coauthored, "Different Schools for a Different World." His passion remains to help teachers explore the affordances of technology for learning and making joy an essential goal for all learners. 